\title{
African American Faith Communities and Public Health:Working at the Intersections of COVID-19
}

Peter Goldblum, PhD, MPH

Palo Alto University https://orcid.org/0000-0002-0186-8288

Floyd Thompkins, Jr., MDiv ( $\nabla$ floyd@jpf.world )

Foundation for Justice and Peace https://orcid.org/0000-0003-4330-8630

Tammy Lai, MBA

Foundation for Justice and Peace https://orcid.org/0000-0002-3992-8442

Lisa M. Brown, PhD, ABPP

Palo Alto University https://orcid.org/0000-0002-3793-7310

\section{Research Article}

Keywords: COVID-19, African American communities, Faith Communities, Trust, Public Health, Structural Racism, Systemic Inequities

Posted Date: November 9th, 2020

DOl: https://doi.org/10.21203/rs.3.rs-101969/v1

License: (1) (1) This work is licensed under a Creative Commons Attribution 4.0 International License. Read Full License 


\section{Abstract}

The unprecendented global disruption caused by COVID-19 has exacerbated systemic inequities in healthcare, public health, socioeconomic status, and structural racism. How systematic inequities that are expressed at the intersection of human activities are addressed will influence whether we can control or stop the pandemic. Priotizing collaboration, equity, and investing financial and social capitol into community leadership is an essential part of mitigating and addressing both the short- and long-term repercussions of COVID-19. Through analysis of and evidence from the lived experiences of a national network of African American pastors, the authors recommend four strategies to expedite recovery from the pandemic and to promote enduring beneficial societal change: (1) public health and faith communities should initiate and maintain ongoing relationships that are based on trust; (2) recognition and acknowledgement by agencies and organizations that faith community leaders possess unique knowledge of their communities; (3) inclusion of faith community leaders as full partners when strategizing, decision-making, problem-solving, and policy development sessions occur that affect community wellbeing; and, (4) use of an intersecting approach that recognizes the multifactorial realities of COVID-19 and uses remedies that effectively address existing and new problems in a comprehensive, long-term manner.

\section{Main Text}

The onslaught of the COVID-19 pandemic has exposed a number of rifts in the social fabric of the United States. Three major areas where this is most immediately evident are as follows: healthcare inequalities, public health failures, and socioeconomic inequalities. Given the unprecedented disruption from COVID19 , finding remedies to these fundamental areas of dysfunction is imperative to avoid having identified rifts widen further and evolve into gulfs. Different pathways, primarily medical or political, have been considered as ways to move forward. These two pathways, however, often ignore the systemic, social, psychological, and organizational behavioral actions that must be addressed to achieve the proposed changes. An efficient and effective response to COVID-19 has been hindered by a lack of strong collaboration, weak and disinterested leadership, disagreement about the function and importance of truth, and an inability to foster inclusive dialogues of trust. Finding practical solutions to these problems that are so evident on local, national, and international levels are further impeded by the increased visibility and impact of anger, hostility, and distrust of people who are racially, politically, regionally, and religiously different from the dominate culture. If we are not able to learn to live and solve problems collectively, our fundamental institutions and traditions are in jeopardy. In the words of Martin Luther King, "We must learn to live together as brothers [and sisters] or perish together as fools." (The Martin Luther King, Jr. Research and Education Institute, 2020).

Since the onset of COVID-19, the Foundation for Peace and Justice(JPF) has regularly convened two national groups of African American pastors from around the country to discuss and analyze the pandemic's impact on African American church communities. Starting in June 2020, one group focused on trauma, and grief has met biweekly. The second group has met intermittently and has concentrated on 
chronicling their experiences and offering insights into the support of their own churches and the various pastoral networks that they serve in a leadership capacity. Both groups are composed of pastors from different denominations and areas of the country. All are leaders who are intentional in fulfilling their traditional roles of serving as trust agents for their respective communities (Thompkins et al., 2020a, $2020 \mathrm{~b}$ ). Their congregants view these pastors as conduits of trustworthy communication, providers of referrals for social services, and negotiators of political engagement. This perspective is supported to varying degrees by public health officials, community mental health leaders, and politicians.

The JPF has a thirty-year history of working with communities in crisis such as Northern Ireland, the West Bank of Israel, and South Africa. JPF's mission is to help communities create or maintain Martin Luther King's idea of the "Beloved Community." Bland and Thompkins (2019) described three tasks of the Foundation in "Tackling Old Problems in New Ways: Reviving the King Legacy in Contemporary Society" as:

1. Fostering dignity

2. Safeguarding livelihoods

3. Encouraging respect

This paper describes insights that have arisen from the experiences of these pastors over the course of the COVID-19 pandemic. These insights augment the evolving Project Trust Model that was described in two recent JPF publications (Thompkins et al. 2020a, 2020b). The Project Trust Model calls for increased use of community-based pastors as trust agents to assist public health and other government agencies that interact with people who are distrustful of their intentions. To date, most of our work has centered on the African American community, given its history of maltreatment and its understandable distrust of medical and government programs. We believe that these lessons also have relevance for other marginalized communities. Using material from interdisciplinary discussions and several case studies, we provide an overview of the heroic efforts by community leaders to contend with evolving public health challenges. In conclusion, we summarize the barriers and principles for engagement between governmental organizations and marginalized communities-especially the African American community-that have promise for improving working relationships.

\section{A Perfect Storm}

The African American community has a long history of suffering social injustice, health and economic inequalities, and the constant and the lingering effects of white supremacy. Pastors, who serve both as spiritual and community leaders, have had to juggle an intense variety of tasks while navigating complicated relationships. Contending with these multiple stressors has given them an intersecting perspective of the present crisis from which some important insights can be gained about the current difficulties as well as the path forward.[1] By intersecting, we mean contending with multifactorial, multileveled challenges, that in turn require expanded pastoral care and problem-solving that takes the 
whole person into account. That is, the biological, psychological, social/cultural, as well as, the spiritual aspect of the personal (Thompkins, 2020b).

The interconnected chronic problems of poverty, violence, health inequities, and discrimination in the African American community, and the pervasive existence of structural racism in the United States are instrumental in affecting social and health disparities and hampering their remedies. With COVID-19 these disparities are evident as increased incidence and prevalence of infection, illness, and death. One explanation for these disparities relates to decreased access to resources and unhealthy work and living environments, that in turn increase the risk for contracting the disease. Moreover, poorer African Americans experience impediments to access of care because of poverty and lack of health insurance. Other environmental factors include increased risk of exposure due to unsafe employment and inadequate housing (Antiga, 2020). Bailey et al.et al (2017), proposed structural racism as a major underlying causative factor in historical disparities in health outcomes among African Americans.

Structural racism refers to the totality of ways in which societies foster racial discrimination through mutually reinforcing systems of housing, education, employment, earnings, benefits, credit, media, health care, and criminal justice. These patterns and practices in turn reinforce discriminatory beliefs, values, and distribution of resources.

While there are no short-term solutions to structural racism, efforts to improve health conditions within specific communities must consider this factor; appreciating that community mistrust, distrust and resistance have comprehensable antecedents (Thompkins, 2020b). Structural racism, particularly as it manifests itself in the public health arena, has undermined the sense of trust that African American people have when it comes to those who are medical professionals. The way the health care system has historically functioned, and the harm it has done to so many African American people, has resulted in a trust deficit. Unfortunately, public health officials and medical professionals continue to operate in ways that continue to widen that gulf. In the midst of a pandemic, these attitudes and behaviors are devastating and cause even more damage to their tenuous relationship with African American communities. If public health officials and medical professionals want to repair these relationships, they need to restructure the systems by which they engage African American communities. Working with African American pastors is one way they can rewire the system in ways that bring authentic and credible voices to the decision making process. It is one way they can begin to repair the breach (A.J. Robinson, personal communication, October 27, 2020). In a world that has demonstrated over and over that African Americans are second-class citizens with little regard for their wellbeing, is it not a surprise that they would seek safety in the storm from trusted members from their own community.

From our discussions with pastors, we are impressed with their tenacity and creativity in light of the paucity of resources for many communities. Their innovation in developing intersecting approaches fosters the health and wellbeing of their communities. These endeavors result in considerable stress as they desperately work to provide accurate information, basic supplies and resources, and spiritual care to their communities. Case 1 is an excellent example of one such spiritual leader working in his community. 


\section{Case 1: A Trusted Spiritual Leader, Looking for Respect}

Rev. Fer-Rell Malone, from Macedonia Missionary Baptist Church in Georgia, demonstrates the heroic efforts made by many African American pastors to help their congregations adjust and cope with COVID19 during a time of social unrest in the United States. It also reveals the frustration with the level of support and respect that they are receiving from governmental agencies. Rev. Malone has already conducted numerous funerals for people who died from COVID-19. For each funeral he has had to negotiate the social distance requirements and restrictions on the number of people who could attend each service. He has suspended all in-person worship services and identified new ways for his congregation to meet and worship together. Rev. Malone has also led the marches and spearheaded the political protest of the murder of Ahmaud Aubrey, an African American young man shot and killed while jogging in a white Georgia community by two white men whom the District Attorney initially determined would not be prosecuted. During this time, police fired upon several children of Malone's congregants. This required him to locate mental health and trauma service providers who could support their families during this distressing time. As the leader of a group of pastors, he also arranged weekly food banks at dozens of churches in order to address food insecurities within the African American community brought about by the economic impact of COVID-19.

Yet, this stalwart minster identified his major frustration about the lack of respect and trust for what he has accomplished by government and social service organizations. He said that he often is not invited to the table when the decisions are being made about public health messaging or implementing food distribution programs. Rather, he had to find his own ways to fulfill these roles. Further, funding and resources were often not available to him as a community leader. While Rev. Malone and his coalition of churches were the vital piece for delivering these essential services to many underserved communities in his area, he and his organization were prevented from receiving or gaining access to public funds by claims that his group lacked expertise in managing governmental contracts. It was because of the overwhelming need of these communities that these churches were forced to find innovative ways to serve their congregations. This "unintentional" and real exclusion was also evident by the lack of dialogue and consultation with Georgia's public health departments. Other pastors echoed this experience of exclusion from meaningful input into planned public health activities and decision-making as well as a lack of respect by and trustworthiness of public officials.

Rev. Malone is an example of a community-based pastor who is a trust agent who assists public health and other arms of government when interacting with the community. As Rev. Malone's works to build essential bridges over the gaps of trust and collaboration, it appears unreciprocated. This likely will impact the long-term efficiency, efficacy, and sustainability of future endeavors initiated by these departments should they continue to refuse to collaborate.

\section{The Need for Community-Public Health Collaboration}

In Lancet, public health policy expert C. Marston and colleagues (2020), made a clear plea for community participation in public health research, policy, and practice to address pandemics: 
Incorporating insights and ideas from diverse communities is central for the coproduction of health, whereby health professionals work together with communities to plan, research, deliver, and evaluate the best possible health promotion and healthcare services...Such community participation matters because unpopular [public health] measures risk low compliance.

These authors identified several areas where community participation provides essential contributions to amplify the effectiveness of public health strategies. Areas that equally apply to the U.S. Tenets of (1) necessity of community trust and knowledge and (2) the need for trustworthy collaboration undergird their plea. They advised public health departments to "(1) show people that their concerns and ideas are heard and acted upon and to (2) collaborate to review outcomes on diverse groups and make improvements" (Marston et al., 2020). To do this they recommend that officials "build on community expertise and networks". Finally, they wisely advised that, "Meaningful relationships between communities and providers should be nurtured to ensure sustained and inclusive participation" and that these efforts at community outreach need to be adequately funded (Marston et al., 2020).

\section{Case 2: An AIDS Success Story: From mistrust to trust and collaboration}

Gay community activist Martin Delaney founded Project Inform in 1985 to advocate for greater access in HIV/AIDS treatments based on the premise that "No one will look out for the Gay Community without being carefully monitored and political pressure." (Delaney \& Goldblum, 1987). Originally Marty took an adversarial stance, mistrusting that national research organizations would prioritize a disease that largely affected the gay community. In early days he squared off with Dr. Anthony Fauci, Director of Infectious Diseases at the National Institute of Health. Their original dispute focused on the FDA process for approval of experimental treatments. After several heated exchanges in which both men were obviously suspicious of the other, they began to listen to each other and found that they respected each other's intelligence and point of view. In 1991 Dr. Fauci invited Marty to sit on the Infectious Disease Council of the $\mathrm{NIH}$ where together they influenced the easing of rules relating to compassionate use of experimental medication among terminally ill patients. In 2009, Marty was given an award by NIH for "extraordinary contributions to framing the HIV research agenda." Throughout his career Marty honored the work of other community political groups like Act Up that continued their agenda to place pressure on governmental organizations to work to end AIDS and respect the civil rights of gay men. Through Project Inform, thousands of people with AIDS have found trustworthy information about AIDS treatments that is based on careful review of options available to them: both experimental and those approved by FDA.

An area of community collaboration that will further challenge our ability to harness public trust related to COVID-19 is vaccine development, acceptability, distribution, and adherence. Shaefer DeRoo (2020) and their colleagues discussed the need for community participation in vaccination programs. They point out that in order to reach herd immunity between $55 \%$ and $82 \%$ of the population must have been exposed to the disease or vaccinated. According to these authors, "a vaccine refusal rate greater than $10 \%$ could significantly impede attainment of this goal." (Shaefer DeRoo et al, 2020). Given the reluctance of some groups to vaccinate their children and the distrust of public health among large segments of the US 
population, attaining these goals will be difficult. Shafer DeRoo and colleagues (2020) noted that in order for programs to increase acceptance and participation in vaccine distribution, programs must be "carefully started before a vaccine becomes available". These efforts must include community representations and trust agents involved at all levels of development and implementation from the beginning. These programs must also take into account community resistance. The Pew Research Foundation reported nearly (49\%) of those polled say "they definitely or probably would not get vaccinated at this time". As of September, 2020, 49\% of those surveyed intend to get a COVID-19 vaccine; that is a decline of $21 \%$ from those surveyed in May, 2020 (Tyson, A. et al, 2020).

Outreach programs must target specific risk groups and use culturally specific strategies. The Kaiser Family Foundation Report, "Race, Health and COVID-19: The Views and Experiences of Black Americans," noted in its executive summary, "About half of Black adults say they would not want to get a coronavirus vaccine if it was deemed safe by scientists and freely available, with safety concerns and distrust cited as the top reasons" (Hamel et al, 2020). Given the history of egregious violations of trust in the area of medical research, the African American community is distrustful of medical researchers with good reasons. In an article entitled, "We won't be guinea pigs: skeptical blacks are balking at pressure to trust and join COVID-19 vaccine trials" (The Final Call, 2020). Led by opposition from the Black Church PAC, the African American community is advised to use great caution before agreeing to participate in vaccine trials. They argue, "Rather than acting in isolation, Blacks need to have a unified front with third party independent verifiers from communities, trusted voices, bioethicists, and scientists to ensure any vaccine is safe" (The Final Call, 2020). Extensive distrust within the African American community of the Trump Administration, further exacerbates the situation. The concerns that arise for vaccine development and distribution also hold true for development and use of COVID-19 therapeutics.

As the movement toward community participation in scientific and ethical oversight of medical research grows, the role of African American clergy must be re-examined. In two previous articles (Thompkins et al, 2020a, 2020b) the Foundation for Justice and Peace has urged African American clergy to take an active role in public health messaging and counseling their congregations' related trustworthy collaboration. While the African American community is not monolithic, the African American church is one the most trusted institutions within that community. Local African American churches, representing a variety of faith traditions provide opportunities to tailor approaches appropriate to their smaller individual congregations.

In moving forward, public health representatives must be sensitive to historical harms inflicted upon the African American community and must undertake meticulous work to transform distrust into trust, a process that will take care and patience, yet one that offers opportunity for significant positive benefits. This process begins by familiarizing oneself with barriers to trustworthy collaboration among public health agencies.

\section{Barriers to Effective Collaboration}


As public health departments reach out to African American communities to develop partnerships in the fight against COVID-19, those who are mindful of the long histories of abuse by medical researcher and the resulting community distrust, will have a higher probability of success. As a start, professionals are wise to examine the history of abuses related to medical research perpetrated upon the African American community (Washington, 2008). This examination will aid officials to better comprehend why many African Americans are distrustful of medical researchers.

\section{Mistrust and Distrust}

In appraising barriers to collaboration between public health providers and community members it is important to distinguish the difference between mistrust and distrust. According to Byron Bland (Thompkins et al, 2020b), "Mistrust arises when one does not know enough about someone to trust him/her. Distrust arises when one expects harm to occur from an encounter. Distrust may be caused by negative personal experiences or from stories told by trusted others. To build trust where there is mistrust is difficult, but to build trust where there is active distrust is much harder because one is forced to counteract one's 'commonsense' experiences that work against trust." The corrective action to combat dis/mistrust centers on being "trustworthy."

Trustworthiness requires truthfulness and consistency in words and deeds To establish trustworthiness, an individual needs to say things and act in ways that instill the belief that he or she is dependable. And this dependability is consistent. Disaffected communities must believe that health care providers "get" them and are sympathetic to their concerns. They also need to feel that they are connected in a "shared future" through the encapsulated interests that define their wellbeing. The implicit question they ask themselves, "Can this person envision me in their future." To answer this each party assesses the trustworthiness of the person in front of them: do you see me as a valued member of your community or are there other solely role related motives,--such as collecting a fee-that drive your kindness.

Francine Brookins, pastor of Beth-El AME Church in Fontana, California described the importance of trust in eliciting participation in community education. Before the need for COVID-19 physical distancing, Rev. Brookins determined that there was a need for bereavement counseling in her church. She contacted a local expert on grief and advertised the start of a grief discussion group within her congregation. She was both surprised and frustrated that no congregant took advantage of this opportunity. After some reflection, Rev. Brookins took a different tack. She announced that she would hold a dinner to check-in on how people were feeling. She received an overwhelming positive response and a group of church members came by for dinner. During dinner she gently moved the discussion to how they felt about the need to support of those who were experiencing bereavement. A personal and deep conversation insued with several suggestions regarding the need for grief support within the church. Several church members volunteered to take the lead in setting up such a group and welcomed the advise from the local grief expert. This example illustrates the need for inclusion, trust, and partnerships in developing effective community programs. 
To initiate a new group, it is often useful to start by making a commitment to establish trustworthiness with specific public health professionals is a starting point. Disciplined communication and openness to self-reflection is critical to engaging in cross-community dialogue. This means that one is keenly aware that "trust gained can be trust lost." Even when mis/distrust has been addressed and a commitment to working together has been established, care in demonstrating respectful discourse and to include community representation in decision-making and planning from the beginning is extremely important. While it may appear to some these efforts of community engagement is an unreasonable luxury during the time of crisis, we have found that the time spent in cultivating these relationships is well spent if barriers are removed and participation in public health initiatives by members of high-risk communities increases.

\section{Lack of Respectful Dialogue}

The need for intergroup discussion is essential in crises in order to identify remedies that work across the board. Whether it is establishing community standards for wearing masks, opening schools, or taking vaccine, the effectiveness of public health strategies depends on finding consensus and support. Given the fractious nature of current community relationships, civility in discourse is at a new low. Among some segments of the population, science and public health in particular are viewed with great suspicion. There has been little effort to reach out to groups who are resistive to basic public health messaging to see if common ground can be found. Even the term "dialogue" has been vilified by some who suggest that "right is right and wrong is wrong; no discussion needed." Some political leaders have tried to take advantage of this rigid divide between our populace. Using mockery and ridicule, each side hurls insults at the other as opposed to working to find common ground; finding ways to establish common ground though is essential in developing public policy that works. Community efforts to have respectful discussion of reponses to COVID-19 that are co-led by community members known for allegiance to opposing positions may be useful. These conversations must be well planned, with work in the selection of participants that are known to be able to listen and communicate respectfully. Having realistic expecations for such conversation is paramount. Leaders must be sensitive to the challenges group members have experienced such as deaths, financial losses, restricted freedom, and inability to have physical contact with others. Their frustration and anger must be validated. Helping people find trustworthy sources of information that comes from sources acceptable to their communities is useful. Sincere respect for these losses, without glib reassurance, may help people experience and come to terms with these changes and move to finding ways to prevent additional loses in their communities.

Another arena that requires respectful dialogue is between public health providers and community trust agents. In our group, several pastors reported displeasure that they were not invited to conversations initiated by public health departments within their community concerning public health messaging. Now several health agencies have determined that the African American churches will be instrumental in providing public health measures to their community (Marston et al, 2020). African American pastors are being called upon to help recruit participates for clinical trials of therapeutics and vaccines. These pastors felt disrespected and felt that relationships need to be repaired before they would trust public 
health professionals to collaborate effectively. Furthermore, rather than forming true partnerships, public health outreach tends to rely on last minute appeals after outreach programs have already been instituted. In many cases these programs were not designed to adequately fit into community member routines. Community members were then asked to fit into the professionals' schedules rather than adapt to community needs. In fact, several pastors indicated that the mistrust that their congregants had before actually turned to distrust when the programs did not take their needs into account. One example was provided to show how tone-deaf public health officials were in speaking with the African American faith community. In a public meeting to discuss the need for social distancing, the public health presenter kept saying to the pastors that "only essential services" were allowed to meet face to face in the early phase of the pandemic. Finally one of the pastors raised his hand noticeably angry, and stated, "Excuse me sir, we happen to believe that our religious services are "essential." This miscommunication could have been avoided had the public health officials had a clearer sense of the values and vernacular of the community.

This mistrust was more than episodic. All of the pastors in our conversations were aware of the role of racism in the communication and sharing of information to and with the African American community. They all reported that they were aware of the gaps in the messaging about the virulence and scope of COVID-19. They suggested that since nurses and doctors within their congregations were the trusted sources of information, that changing messaging from the federal government or the CDC had little affect on their comprehension of the virus and how to protect themselves and their families.

\section{Provider and Community Stress and Time-Urgency}

Presiding Elder Eloise Knox, of the Chritian Methodist Episcopal (CME) church, commented on her need to miss one of the online sessions, "I am too overwhelmed", adding that "her sense of vulnerability during the COVID-19 pandemic was a symptom of the daily struggle that African Americans have in general for accessing general health care." The current crisis just adds another level of complexity to an already dire situation.

In times of crisis we are called upon to go above and beyond our usual day-to-day efforts. When a crisis is prolonged as it is with COVID-19, crisis management becomes the status quo. In a seminal theory of stress management, R.Lazarus and S. Folkman (1984) propose a stress and coping model stating that "stress is the feeling of tension or pressure experienced when we perceive that the demands being placed upon us exceed the resources we have to meet them" (Delaney, M. \& Goldblum, P., 1987). COVID-19 places great demands on both public health providers and clergy. Strategies to cope with these demands may differ from person to person; some being more effective than others. In JPF's online seminar with pastors and health providers, Rev. J. Sommerville (Thompkins et al, 2020) described why clergy might not heed the need to reduce demands and increase stress management practices. As the stalwarts of the community, pastors may have an unrealistic expectation of themselves, shared by their congregants, that they are the calm within the storm. Likewise, public health providers may feel overwhelmed by the many activities required to establish community based prevention and treatment services. To make matters 
worse, both professionals and community leaders are generally under-funded, requiring difficult decisions about the allocationof resources.

A key component of stress is the sense of time urgency; so much to do with so little time to do it. This time urgency can distort our perception and determination of the best way to proceed. As the stress management experts suggest , "We should work smarter, not harder." Part of this smarter approach is an accurate appraisal of sources of support. Another aspect that is central to the serenity prayer is control. We are encouraged to know what demands are under our control and which are not. This then allows us to focus our efforts decreasing or eliminating things that are changeable and to find emotionally focused coping strategies to accept those that are outside of our control. In any case, it is helpful to have a plan of action to organize our strategy. This plan may include proactive measures to enlist community resources to assist in public health measures and to reduce resistance to one's efforts. In other words, enlisting community support in Covid strategies is a way to work smart.

\section{Principles for Trustworthy Community Engagement and Collaboration}

In a recent paper entitled African American Churches as First and Last Responders in the Era of COVID-19, Thompkins and colleagues (2020b) described the Project Trust Model; a collaborative model encouraging an ecological approach for incorporating African American pastors into the fight against COVID-19. Underlying that model is an ethos known as "ubuntu", an African term for community relations described by J. Goosby Smith and J.B. Lindsay (2014) in Beyond Inclusion: Work life Interconnectiveness, Energy, and Resilience in Organizations. In their words "...one's existence as a person is conceptualized as being embedded in one's cultural context" and embodied by the phrases, "I am because you are" and "When you suffer, I suffer, when you thrive, I thrive." This philosophy is closely aligned with Martin Luther King, Jr.'s idea of the "Beloved Community."

We believe a shift in worldview aligned with Ubuntu is required to address the barriers to collaboration outlined in the previous section. This view is exactly opposite from one that separates communities and those who serve them into discrete silos, with little or no interaction between them. Historically marketplaces ("Agora" in Greek) were often created at "intersections" of multiple thoroughfares and trade routes (Lindenlauf, 2014). The Agora were hubs of activity of its citizens: their daily religious, political, judicial, social and commerce. The growth of the marketplace better allowed "cross cultural exchange" and facilitated growth in commerce and learning. We believe that when various aspects of community life meet together they will better be able to develop networks that can find solutions to community problems that benefit from divergent points of view. We suggest that pastors and public health providers meet and work at the intersection and identify hubs that benefit from multifaceted discourse and collaboration. Several examples of covid related hubs are: public health messaging, vaccine and therapeutic development and distribution, end of life/bereavement support, the impact of poverty and violence on community health. By bringing multiple voices together in respectful dialogue, more nuanced and effective strategies for coping with the pandemic can be created.

\section{Principle 1: Public Health and Faith Communities should maintain ongoing trustworthy relationships.}


Rather than waiting until a crisis occurs, bridges should be built to manage the health and wellbeing of the community and to provide ongoing feedback as to how public health providers can best serve the community. Programs initiated by community groups that provide needed aid should be encouraged and where possible financially backed. These relationship should be "two way" rather than seen as only eliciting support for professional public health initiatives. This outreach should include identification of "Trust Agents" and seeking their council. Ongoing community health programs that support health promotion and disease prevention provide opportunities to address areas of mistrust. By taking an ecological view (Bronfenbrenner, 1979) the impact of community-level distress such as poverty, food insecurity, violence, and educational problems can be analyzed and addressed by community coalitions. Trust cannot be built overnight. Trustworthiness must be earned. Changing mistrust or distrust requires intentional action. An interesting example of community mistrust came during one of Project Trust's training workshops for pastors. The subject of public mental health response to a recent fatal shooting came up in discussion. A witness at the scene was distressed that a call to Trauma Services was not answered. Many in the room took this as an example of another betrayal by the health department. Later, after some investigation, it was discovered that a community member who was working for emergency services had come to the scene of the shooting, but presented herself as a community member rather than being there officially. With clearer communication, the department would have gotten credit and their concern could be expressed to members of the community. When COVID-19 hit the African American community of San Francisco, a scramble by public health department to establish relationships with the African American community, left many in the community wondering where they had been beforehand.

\section{Principle 2: Faith Community leaders should be acknowledged for having unique knowledge of their communities and brought into strategizing, decision-making and problem solving, and policy development early as full partners.}

As new public health crises, such as COVID-19, arise that require community participation; community trust agents should be included in the community-based public health strategy. Knowing community resources and expertise beforehand will save a great deal of time and assure that the proper community leaders be consulted. Through their assessment of community values and sensitivities, public health messages can be crafted that bring the best known science to groups at risk. As public health science discovers the need for changed messaging, community trust partners can assist in finding the best vehicles for telecasting these changes. An example of the potential use of African American pastors as trust agents is in COVID-19 vaccine development and distribution. Early studies indicate concern that African Americans are resisting participation in clinical trials for COVID-19 vaccine. Further, concern that even when vaccines are approved that large segments of African Americans at increased risk for contracting the disease, may resist being vaccinated. This situation requires not only that identified Trust Agents vouch for vaccines, it requires transparency (honesty) in carefully reviewing the scientific data to determine what information is trustworthy. Extreme care must be taken by medical researchers and public health officials not to be perceived as "conning" the community, especially in dealing with the African American community that has real examples of unconscionable manipulation of research subject. 


\section{Principle 3: Take an Intersecting Approach that recognizes the multifactorial realities of COVID-19 era challenges and uses remedies that address problems in a comprehensive manner.}

In this paper we have identified the interplay of community and individual level stressors-some new some long-standing-and the need for collaborative strategies to address these stressors. The complexity of demands requires integrative approaches to care. An intersecting approach to care requires professionals leave their silos and learn to collaborate for the benefit of their clients/patients/congregants. An example that has been discussed in our Funeral Program is the need to develop networks with pastors, end of life medical teams, funeral homes, and mental health providers to address the changes required in after death care. The discussion began by considering the changes needed due to social distancing at funerals. As these discussions continued, discussion centered on what could be expected during end of life medical care for COVID-19 and from funeral service professionals. Given the rapid deterioration for those with terminal COVID-19, issues pertaining to advanced directives were addressed. They discussed the need for pastors and chaplains to take up slack in making sure that families are prepared for imminent death, given that the demand on hospitals may be extreme and patient contact with families disrupted,. Significant differences were uncovered regarding what one can expect from mortuary and funeral home companies. Some provide extensive support and education regarding emotional and practical needs of families. Others are more spare and focus primarily on disposal of the body. Pastors are often called upon to go beyond the ritual of burial and provide ongoing emotional support and assessment of potential complications in the grief process. Thus pastors need to be trained to identify problematic grief and know the appropriate mental health resources to address these situations.

\section{Principle 4: Even during a crisis, take the long view of impact on marginalized communities.}

While time urgency and provider stress may seem to require taking short cuts in providing collaborative care, these "bandaids" may not serve well in the long run. As a public health nurse said at the end of the first year of the AIDS crisis, "We've moved beyond the panic stage to crisis as usual" (B. Faltz, RN, personal communication,1985). Taking the long view means attending to the long-term effect on communities directly and indirectly impacted by the current crisis. Individuals and organizations must ask, "Was the community's ability to sustain itself enhanced or diminished?" Additionally, one must ask, "What impact did the crisis have on the welfare of children in the community?" One of our program leaders, Dr. D. Armstrong, ordained minister, public policy expert, and mental health counselor, championed awareness of the downstream mental health impacts of the pandemic. Dr. Armstrong recommended that children be evaluated with the Adverse Childhood Experience (ACEs) test to determine their level of trauma and to initiate trauma-based programs for those identified (CDC, 2020).

\section{Case 3: Faith Communities and COVID-19: An Intersecting Approach}

In a video interview conducted by Rev. Floyd Thompkins, Bishop Ernie Jackson described what he called a "new way of pastoring." By this he meant, confronting multiple challenges requires pastors to engage in expanded roles, including promotion of physical and mental health, and the reduction of poverty and 
violence. This new pastoring requires altering spiritual work "as usual". With deep compassion and wisdom, he envisions social problems as intersections and seeks remedies that take into account the biological, psychological, social, cultural and spiritual aspects.

The bishop's transformation to new roles did not begin with his confrontation of COVID-19. Following in the historical footsteps of African American ministers working as champions of civil rights and as political forces within their communities, he is well known in the halls of government in San Francisco. He served in the administration of Willie Brown, San Francisco's first African American mayor. Over the years he has been an active community leader in efforts to bring social justice to the residents of the Bayview-Hunters Point district known for its poverty and health problem, including environmental illness due to several toxic waste dumps. He is a living example of spiritual leader as trust agent.

In 2018, he joined Project Trust, a community based project to encourage African American pastors to better address mental health problems by finding ways for their churches to help reduce its stigma and provide outreach to those in their congregations with unmet mental health needs. This project included dialogue and collaboration between clergy and mental health providers in order to expand their working relationships.

Unlike many African American pastors, Bishop Jackson's congregation, the Grace Tabernacle Community Church, has not experienced multiple COVID-19 deaths, perhaps due to their early adoption of online services and limiting face- to-face contact among congregants. He has been outspoken, though, in the need for churches to expand their programs to assist families cope with the pandemic. He and his fellow pastors have handed out over 75,000 meals since the beginning of the pandemic for children in need. During this time, he has officiated multiple funerals from gun violence and other causes requiring extra sensitivity in providing succor while protecting mourners from contagion. He laments the socialdistancing restrictions placed on mourners, "Not going to the funeral service, not getting a program in your hand, reminiscing, viewing the body, seeing the flowers at the grave site," all of these rituals help bring closure to mourners.

When asked for his thoughts regarding ministers who continue to encourage close personal contact in church and who provide scriptural justification to continue in-person activity and contact, he was not hesitant in challenging these pastors by saying, "We need to ask what God is trying to tell us." As a biblical scholar he asks us to remember that the original Christians met in homes. "The church is not just a building." He challenges us to contemplate, "What is faith?" and to work to find new ways to preserve the sanctity of life.

As evinced by the narrative of Bishop Ernie Jackson's intersecting work, a long term approach has been taken that addresses crises that have multi-generational effect, that are at the intersection of public and mental health, and navigate the violence and disenfranchisement of marginalized communities. Leadership for community development and health programs is best originated within the community. Public health has an essential role to play and certainly public funding will be required to sustain 
programs within impoverished communities, only through community leadership will we go beyond colonialism to full enfranchisement.

[1] The authors have selected the term "intersecting", rather than "intersectional", a term coined by Crenshaw(1989) that suggests that people with multiple stigmatized identities experience unique impacts, including potential sources of resilience.

\section{Conclusion}

Several models for the COVID-19 pandemic have been constructed using different parameters to determine the probable course of the pandemic. It is clear, that abiding by basic public health recommendations have a differential effect on the reduction in morbidity and mortality (Reiner et al., 2020). What these models do not portray is the intersecting social, economic, and political impacts of the disease and the efficacy of chosen responses to it. The cost of the disease is catastrophic. While we can debate whether other political and public health strategies would have made things worse or better, it is evident that our basic social, economic, social justice, and public health systems are strikingly unprepared and perhaps broken. COVID-19 can be compared to the stress tests that the government conducted with banks after the 2008 recession; using that analogy, we have failed. Without urgent, careful, and sustained effort by both the government and community members, we are at risk of economic and health collapse. Some have used the term, "Tsunami."

COVID-19 has had a disproportionately negative effect on the most vulnerable groups in our society. Remedies to correct these disparities need to take into account community traditions, sensitivities, resources, and levels of trust of medical and public health authority. In the work conducted by the Foundation for Justice and Peace, outreach to African American pastors has been undertaken to find culturally specific approaches tailored to that community with hope that this work with provide an example for work other marginalized groups.

In fact, how we resolve the issues of human activities discussed in this paper will determine whether we can stop this pandemic; Science alone will not defeat COVID-19. The fate of the economy, our health system, and our governance are at stake in addressing these issues. Prioritizing collaboration, equity, and investing financial and social capital into community leadership is an essential part of the COVID-19 cure. In the final analysis, our ability to survive is conditioned on innovative collaboration and intersecting approaches that address these four human arenas:
1. Experience and acceptance of loss
2. Create and envision a shared future
3. Demonstrate trustworthiness
4. Rectify injustice

Crisis places us at a crossroads. If we ignore the messages and avoid taking corrective action, our future is in peril. If we heed the messages and respond courageously, we have the opportunity to grow from it 
and get better. Right now, the future of our country lies in the balance.

\section{Declarations}

Ethics: This study was reviewed by the Palo Alto University Institutional Review Board who ruled that IRB approval is not required for this project as it is not human subjects research.

Consent: Informed consent was obtained from all individual participants involved in the study.

Funding: None declared

Conflicts of interest/Competing interests (include appropriate disclosures): None declared

Availability of data and material (data transparency): Data available on request from authors. The data that support the findings of this study are available from the corresponding author, [PBG], upon reasonable request.

Code availability (software application or custom code): None declared

\section{References}

Antiga, S., Garfield, R, Orgers, K. (2020, April 7). Communities of color at higher risk for health and economic challenges due to Covid-19. KFF. https://www.kff.org/coronavirus-covid-19/issuebrief/communities-of-color-at-higher-risk-for-health-and-economic-challenges-due-to-covid-19/? utm_campaign=KFF-2020Uninsured\&utm_source=hs_email\&utm_medium=email\&utm_content=2\&_hsenc=p2ANqtz_UqLloowVMibewUsBF8kGfwkh4ndUc-Ng7RZ8if-KZNFdsVsWt8UG2un7FH2DxliVe3nEefuXSQR1155GRclUWd7mg\&_hsmi=2

Bailey, Z, Krieger, N., Agenor, M, Graves, J, Linos, N, Bassett, M. (2017, April 8). Structural racism and health inequities in the USA: evidence and interventions. The Lancet,389(10077), 1453-1463. https://doi.org/10.1016/S0140-6736(17)30569-X

Center for Disease Control. (2020). Adverse Childhood Experiences (ACEs). Retrieved from. https://www.cdc.gov/violenceprevention/aces/index.html

Crenshaw, K. (1989). Demarginalizing the Intersection of Race and Sex: A Black Feminist Critique ofAntidiscrimination Doctrine, Feminist Theory and Antiracist Politics, University of Chicago Legal Forum,1989(8). http://chicagounbound.uchicago.edu/uclf/vol1989/iss1/8

Delaney, M. \& Goldblum, P. (1987) Strategies for survival: A gay mens' health manual for the age of aids. St Martins: New York. 
Hamel, L. Lopes, L. Muñana, C., Artiga, S., \& Brodie, M. (2020). Race, Health, and COVID-19: the Views and Experiences of African Americans. Kaiser Family Foundation. http://files.kff.org/attachment/Report-RaceHealth-and-COVID-19-The-Views-and-Experiences-of-Black-Americans.pdf

Lazarus, R.S. \& Folkman, S. (1984). Stress, Appraisal, and Coping. New York: Springer Publishing Company.

Lindenlauf A. (2014) Agora in the Greek World. In: Smith C. (eds) Encyclopedia of Global Archaeology. Springer, New York, NY. https://doi.org/10.1007/978-1-4419-0465-2_1428

Marston, C., Renedo, A., Miles, S., (2020, May 30) Community participation is crucial in pandemic. Lancet, 395(10238), 1676-1678. doi: 10.1016/S0140-6736(20)31054-0

Reiner, R.C., Barber, R.M., Collins, J.K. et al. (2020, October 23). Modeling COVID-19 scenarios for the United States. Nature Medicine (2020). https://doi.org/10.1038/s41591-020-1132-9

Schaffer DeRoo, S., Pudalov, N.J., Fu, L.Y. (2020, May 18). Planning for a COVID-19 Vaccination Program. JAMA,323(24),2458-2459. doi:10.1001/jama.2020.8711

Smith, J.G.\& Lindsay, J.B. (2014). Beyond Inclusion: Worklife Interconnectedness, Energy, and Resilience in Organizations. Macmillan: New York

The Final Call. (2020). We won't be guinea pics: Skeptical blacks are balking at pressure to trust and join COVID-19 vaccine trials. https://new.finalcall.com/2020/09/15/we-wont-be-guinea-pigs-skeptical-blacksare-balking-at-pressure-to-trust-and-join-covid-19-vaccine-trials/

The Martin Luther King, Jr. Research and Education Institute. (2020). Remaining Awake Through a Great Revolution. Stanford University. Retrieved from https://kinginstitute.stanford.edu/kingpapers/publications/knock-midnight-inspiration-great-sermons-reverend-martin-luther-king-jr-10

Thompkins, F. \& Bland, B. (2019, November 18). Tackling Old Problems in New Ways Reviving the King Legacy in Contemporary Society. Unpublished manuscript. https://jpf.world/wpcontent/uploads/2020/02/Final-JPF-Seminars-Intro-2.0.pdf

Thompkins, F., Jr., Goldblum, P., Lai, T., Hansell, T., Barclay, A., \& Brown, L. M. (2020a). A culturally specific mental health and spirituality approach for African Americans facing the COVID-19 pandemic. Psychological Trauma: Theory, Research, Practice, and Policy, 12(5), 455-456. http://dx.doi.org/10.1037/tra0000841

Thompkins, F, Goldblum, P, Armstrong, D., Fuqua, V., Lai, T., Allen, D., Sommerville, J., Brown, L.M. (2020b). African American Churches as First Responders and Last Responders in the Era of COVID-19. Manuscript submitted for publication. 
Tyson, A. Johnson, C. \& Funk, C. (2020, September 17). U.S. Public Now Divided Over Whether to Get COVID019 Vaccine. Pew Research Center. https://www.pewresearch.org/science/2020/09/17/u-s-publicnow-divided-over-whether-to-get-covid-19-vaccine/

Washington, H.A. (2008). Medical Apartheid: The Dark History of Medical Experimentation On Black Americans from Colonial Times to the Present. New York: Doubleday.

\section{Appendix}

Table 1. Churches that participate in JPF's COVID-19 groups

\begin{tabular}{|lll|}
\hline Church & City & State \\
\hline Bell Chapel CME Church & San Francisco & California \\
\hline Grace Tabernacle Community Church & San Francisco & California \\
\hline City of Refuge UCC & Oakland & California \\
\hline Beth-EL AME Church & Fontana & California \\
\hline Holy Light Missionary Baptist Church & Los Angeles & California \\
\hline St. Stephen's Lutheran Church & Chicago & Illinois \\
\hline Siloam Presbyterian Church & Brooklyn & New York \\
\hline Shiloh Baptist Church & Trenton & New Jersey \\
\hline Scripture Cathedral Ministries & Landover & Maryland \\
\hline Gillfield Baptist Church & Petersburg & Virginia \\
\hline Refuge Temple Church & Burlington & North Carolina \\
\hline Arise Church of Atlanta & Decatur & Georgia \\
\hline Macedonia Missionary Baptist Church & Waycross & Georgia \\
\hline
\end{tabular}

